\title{
Presence of a functional vitamin D receptor does not correlate with vitamin D3 phenotypic effects in myeloid differentiation
}

\author{
Alexis Grande ${ }^{1}$, Rossella Manfredini ${ }^{1}$, Michela Pizzanelli ${ }^{1}$, \\ Enrico Tagliafico ${ }^{1}$, Raffaella Balestri ${ }^{1}$, Francesca Trevisan ${ }^{1}$, \\ Daniela Barbieri ${ }^{2}$, Claudio Franceschi ${ }^{2}$, Renata Battini ${ }^{1}$, \\ Stefano Ferrari ${ }^{1}$ and Sergio Ferrari ${ }^{1,3}$ \\ ${ }^{1}$ Dipartimento di Scienze Biomediche, Sezione di Chimica Biologica, Università \\ di Modena, Italy \\ 2 Dipartimento di Scienze Biomediche, Sezione di Patologia Generale, Università \\ di Modena, Italy \\ 3 corresponding author: Sergio Ferrari, Dipartimento di Scienze Biomediche, \\ Sezione di Chimica Biologica, Università di Modena, 41100 Modena, Italy. \\ tel: ++39 59 428514; fax: ++39 59 428524; e-mail: sergio@unimo.it
}

Received: 11.2.97; revised: 9.4.97; accepted 14.4.97

Edited by G. Melino

\begin{abstract}
Although VDR is expressed in all the acute myeloid leukemia cell populations studied, most of these leukemias do not exibit any phenotypic response when exposed to VD. To determine whether VD resistance is related to an altered VDR function, we performed an analysis of VDR expression, phosphorylation, DNA binding capacity and transactivation activity in several leukemic myeloid cell lines arrested at different levels of maturation. Our results indicate that VD induces a clear phenotypic effect, i.e. terminal monocytic differentiation, only in leukemic cells of M2/M3 (intermediate myeloblasts) and M5 (monoblasts) types but not in erythroid precursor cells, early leukemic myeloblasts (M0/M1 type) and promyelocytes (M3 type). VDR expression and function are evident in all the nuclear extracts obtained from the different myeloid cell lines after $12 \mathrm{~h}$ of VD treatment, but VD activation of monocytic differentiation is limited to a narrow differentiation window characterized by the M2 type myeloid cellular context.
\end{abstract}

Keywords: monocytic differentiation, vitamin D receptor, 1,25 dihydroxyvitamin D3, Acute Myeloid Leukemia, transcriptional factors, DNA binding proteins

Abbreviations: AML, acute myeloid leukemia; DMSO, dimethyl sulfoxide; ATRA, all-trans-retinoic acid; VD, 1,25dihydroxyvitamin D3; TPA, 12-O-tetradecanoylphorbol 13acetate; APL, acute promyelocytic leukemia; VDRE, vitamin $D$ responsive element; $R X R$, retinoid $X$ receptor; CIAP, calf intestinal alkaline phosphatase; EMSA, electrophoretic mobility shift assays; hOC, human Osteocalcin; HMSE-1, human monocyte/macrophage serine esterase 1; FAB, French American British; FCS, fetal calf serum; RT-PCR, reverse transcription-polymerase chain reaction; MGG, May Grunwald Giemsa; PMSF, phenylmethylsulfonylfluoride; NP-40, Nonidet
P-40; PAGE, polyacrylamide gel electrophoresis, HRP, horseradish peroxydase; CAT, chloramphenicol acetyltransferase; ROS, Rat Osteosarcoma; $\beta \mathrm{GAL}, \beta$ galactosidase

\section{Introduction}

Acute myeloid leukemias (AML) are characterized by blast cells which are unable to mature into functional, terminally differentiated cells. A small percentage of leukemic blast cells remains in the proliferative pool in the bone marrow microenvironment and constitutes the growth fraction, but the large majority of these cells, especially in the peripheral compartment, are mainly arrested in the G1 phase of the cell cycle (Ferrari et al, 1986, 1989), have a long survival rate, and are not capable of efficiently activating programmed cell death (Torelli et al, 1994). Inducing leukemic cells to differentiate and therefore undergo apoptosis, provides an opportunity to modify the course of the malignancy.

The FAB classification of acute leukemias, based on morphology and cytochemical analysis of specific enzymes (Bennett et al, 1976), and the immunological classification based on the immunophenotype (Drexler, 1987) have clearly shown that the maturation arrest of AML blast cells occurs at different stages along the differentiation pathway. Several myeloid cell lines have been established from blast cell populations obtained from patients with AML (Miller and Koeffler, 1990) and despite the fact that these cell lines have a high proliferative capacity, they maintain the differentiation block characteristic of the parental leukemic cells from which they were derived. Therefore these leukemic cell lines are an interesting in vitro model for studying the pathways and for identifying the genes involved in myeloid differentiation (Lubbert et al, 1991).

Among the several compounds which have been identified which can overcome the differentiation block of acute leukemic blast cells, the most extensively studied are dimethyl sulfoxide (DMSO), butyrate, all-trans-retinoic acid (ATRA), 1,25-dihydroxyvitamin D3 (VD) and 12-O-tetradecanoylphorbol 13-acetate (TPA) (Lea, 1992). VD and ATRA are differentiation inducers active on myeloid hematopietic cells not only in vitro but also in physiological microenvironments (Pols et al, 1990; De Luca, 1991). It has been shown that 'differentiation windows' exist (Francis and Cunningham, 1991), within which the cells are sensitive to the different inducers, since the differentiation capacity of leukemic myeloid cells is related both to the level of maturation arrest and to the proliferative rate (Ferrari et al, 1990). An important example of differentiation therapy in AML is provided by ATRA which is a powerful inducer of granulocytic differentiation in acute promyelocytic leukemia (APL). In fact, when administered as a single agent, ATRA 
can induce complete clinical remission in patients with APL (Castaigne et al, 1990; Warrell et al, 1991) even if subtypes of this leukemia might be spontaneously unresponsive to treatment due to the presence of mutation in the RAR $\alpha$ gene (Dore and Momparler, 1996), to a loss of expression of the intact pml/RAR $\alpha$ protein (Dermime et al, 1993), or acquire resistance to a second ATRA-induction therapy (Delva et al, 1993).

VD and VD analogues (Imai et al, 1995) have been shown to be active in vitro and in vivo models, raising the possibility of their use in the differentiation treatment of human malignancies (Kasukabe et al, 1987; Kelsey et al, 1992). Although the concentrations of VD that optimally induce differentiation in vitro models are at least three orders of magnitude higher than normal physiological serum levels, the hormone acts synergistically with cytokines and growth factors in vitro, suggesting that it may play a role in the control of normal hematopoiesis (Trinchieri et al, 1987; Okabe-Kado et al, 1991; Kelsey et al, 1992; Duits et al, 1992). It is well known that VD exerts its action by binding to a specific nuclear receptor (VDR) with high affinity. VDR regulates gene expression in target cells by binding to a specific DNA responsive element (VDRE), via heterodimerization with Retinoid X receptor (RXR) (Hsieh et al, 1995; Jin et al, 1996; Lemon and Freedman, 1996).

To better evaluate the relationship between VDR function and VD phenotypic effects and therefore to get useful information on the nature of the differentiation block which occur in AML blast cells, we have studied VDR expression, DNA binding and transactivation activity in several myeloid leukemic cell lines arrested at different levels of maturation.

\section{Results}

\section{Differentiation effects of VD on myeloid cell lines arrested at different levels of maturation}

Monocytic differentiation has been evaluated after five days of treatment with $10^{-7} \mathrm{M} \mathrm{VD}$, by monitoring morphology, cell adhesion capacity and CD14 protein induction. As shown in Figure 1, immature myeloblastic cell lines such as K562 (myelo-erythroblastic), KG-1a and KG-1 (M0-M1 types), and the more differentiated promyelocytic cell line NB4 (M3 type) are not responsive to the differentiation effects of VD, since no induction of CD14 protein occurs after 5 days of VD treatment (Zhang et al, 1994). The more mature myeloblastic cell lines, such as AML-1 and HL-60 (M2-M3 types), monoblastic THP-1 (M5 type) and U937 (histiocytic) cell lines, and spontaneous blast cells of M5 type, are sensitive to VD since a clear induction of CD14 is detected. The levels of expression of CD45 protein (Thomas, 1989) remain unmodified before and after VD treatment, indicating good cell viability. Furthermore, no morphological and functional changes are evident in the unresponsive myeloid cells, while responsive cells develop the adhesion capacity and assume monocyte morphology after 5 days of VD treatment (data not shown).

\section{VDR expression and phosphorylation}

Western blot analysis reveals an immunoreactive VDR band in the nuclear extracts of all cell lines (Figure 2A) and of AML cells (M5 type) obtained from a patient (Figure 2C, lane 12). VD treatment is crucial for VDR detection, since nuclear extracts obtained from untreated cells do not contain VDR detectable by Western blot analysis (data not shown and

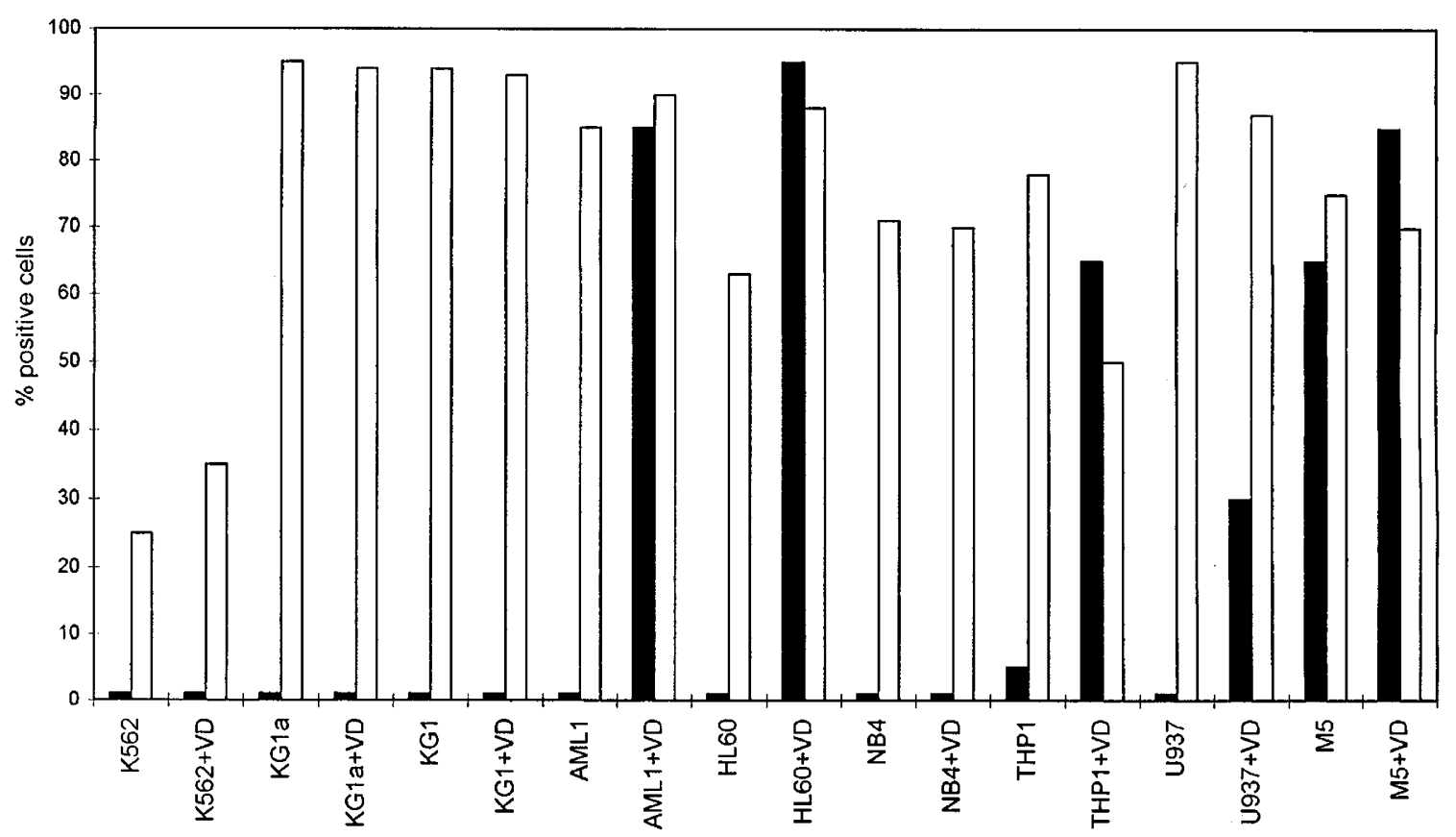

Figure 1 Flow cytometric analysis of CD14 (black bar) and CD45 (open bar) antigens expression in leukemic myeloid cell lines induced to monocytic differentiation with VD. The expression levels of these antigens are reported as percentage of positive cells. The cell lines studied are indicated at the bottom of the histogram. Three different sets of experiments were performed and the variability of positive cells, in each experiment, was lower than $10 \%$. VD treatment was carried on for 5 days. 
Figure 2C, compare lanes 11 and 12). The results shown in Figure 2A, allow two main observations: (a) a wide variability in VDR levels exists among the cell lines studied, in particular K562 and KG-1a appear to contain very little VDR; (b) the apparent molecular weight of VDR is not homogeneous in different cell types. Since it is known that VDR is a phosphoprotein (Brown and DeLuca, 1990; Suggs et al, 1992), we have investigated whether phosphorylation might be the basis for this size variability. Indeed, calf intestinal alkaline phosphatase (CIAP) treatment of KG-1 nuclear extracts leads to the detection of a VDR band (Figure 2B, lane 10) which is approximately $1 \mathrm{Kd}$ smaller than in the untreated nuclear extract (lane 9). We estimated a MW of $52 \mathrm{Kd}$ and $53 \mathrm{Kd}$ for CIAP-treated and untreated control respectively. Quite interestingly the more phosphorylated VDR forms were present in cell lines which are not responsive to VD (Figure 2A, lanes 1, 2, 3 and 6).

\section{DNA binding activity of VDR}

Since all cell lines, either responsive or unresponsive to VD treatment contain VDR, albeit with different abundance and phosphorylation levels, we investigated the functional ability of the VDR present in nuclear extracts to bind its cognate DNA responsive element (VDRE). Oligonucleotides containing a VDRE like DR3, or rat and human osteocalcin DR-3 type responsive elements (Umesono et al, 1991; Ozono et al, 1990) were used as probes in electrophoretic mobility shift assays (EMSA). The presence of VDR in shifted complexes was assessed by using a monoclonal antibody (Ab)

A

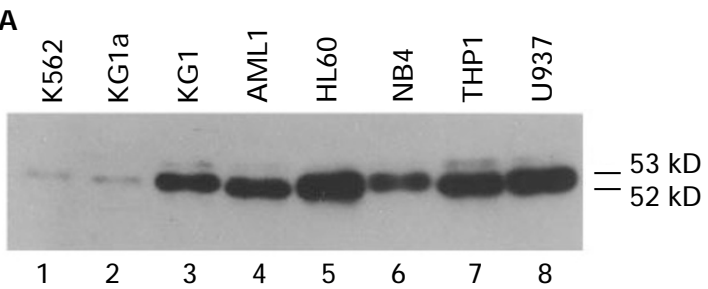

B

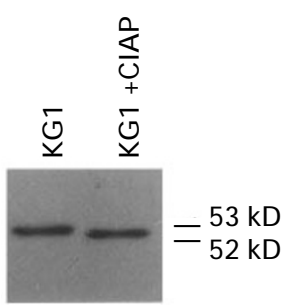

$9 \quad 10$

Figure 2 Western blot analysis of VDR expression in nuclear extracts of different leukemic myeloid cells after $12 \mathrm{~h}$ VD treatment (A, lanes 1 to 8 ). The leukemic myeloid cell lines are indicated at the top of the panel. (B) shows the Western blot analysis comparing VDR protein size in CIAP untreated (lane 9) and treated (lane 10) KG1 nuclear extracts obtained after $12 \mathrm{~h}$ of VD treatment. (C) VDR protein expression in nuclear extracts of spontaneous AML-M5 type blast cells before (lane 11) and after (lane 12) 12h VD treatment. Molecular weights of VDR protein are reported on the right side of each panel. specifically directed to VDR. Figure 3 shows that, using DR3 oligonucleotide, a major complex containing VDR (indicated by the arrow) is present in all cell lines and in

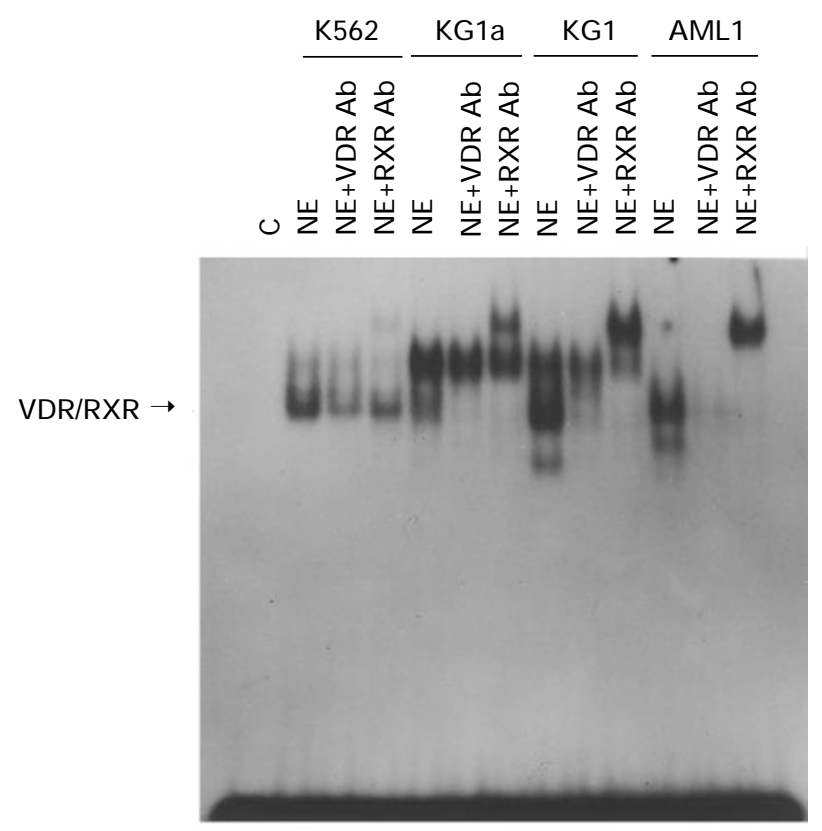

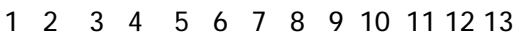
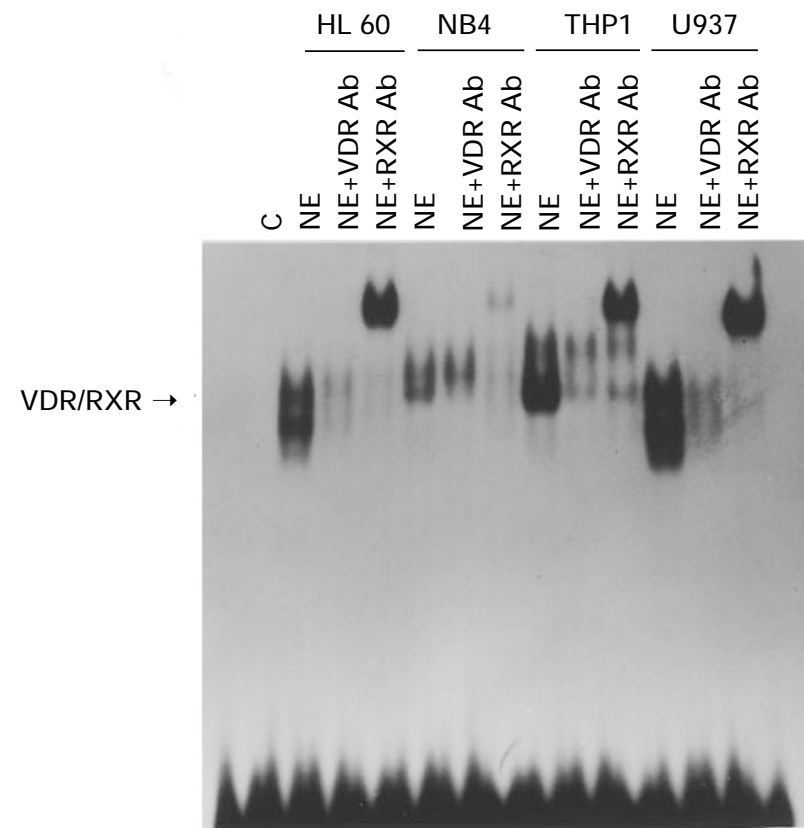

14151617181920212223242526

Figure 3 EMSA analysis on nuclear extracts obtained from myeloid cell lines after $12 \mathrm{~h}$ VD treatment using ${ }^{32} \mathrm{P}$-labeled DR3 probe: lanes 1 and 14 , DR-3 unincubated oligonucleotide; lane 2, K562 cells; lane 5, KG1a cells; lane 8, KG1 cells; lane 11, AML1 cells; lane 15, HL60 cells; lane 18, NB4 cells; lane 21, THP1 cells; lane 24, U937 cells. To evaluate the VDR containing complexes, an anti VDR monoclonal $\mathrm{Ab}$ was added to the different nuclear extracts (lanes 3, 6, 9, 12, 16, 19, 22, 25). The presence of RXR protein was assessed by an antibody against RXR $\alpha, \beta, \gamma$ (RXRAb) (lanes 4, 7, 10, 13, 17 , $20,23,26)$. The arrow indicates the major gel shift complex containing VDR/ RXR heterodimer. 
spontaneous leukemic blast cells of M5 type (data not shown). As it is expected from the use of a DR3 type probe, the VDR containing complex also contains a member of the Retinoid $X$ receptor (RXR) family. In fact $R X R$ is known to heterodimerize with VDR in binding this type of VDRE (Umesono et al, 1991). In myelo-erythroid precursor K562 cells, the major retarded complex is evident (Figure 3, upper panel, lane 2), which however contains very little VDR/RXR heterodimer. In fact, only a small reduction of the complex is detected with anti VDR Ab (lane 3) and consequently a faint supershifted band is observed with anti RXR Ab (lane 4). This result is compatible with the low VDR protein abundance in the nuclear extract shown by the immunoblot analysis. In the early myeloblastic cell lines KG-1a and KG-1, which are not responsive to VD, two major complexes are detected (Figure 3, upper panel, lanes 5 to 10), but only the lower one (indicated by the arrow) contains VDR/ RXR heterodimers as judged by the effect of the anti VDR Ab (lanes 6 and 9), and the anti RXR Ab (lanes 7 and 10). A very similar EMSA pattern is observed in NB4 and THP-1 nuclear extracts (Figure 3, lower panel, lanes 18 to 23). Finally nuclear extracts from KG-1, AML-1, HL-60 and U937, in addition to the main retarded complex, also contain other faster mobility complexes which are VDR/RXR related and probably depend on the presence of different $R X R$ isoforms (Hsieh et al, 1995) or to proteolysis of either VDR and/or RXR in the nuclear extracts. The same results were obtained using the rat and human osteocalcin natural VDRE (data not shown).

\section{Ability of endogenous VDR to activate transcription of VDRE-dependent promoters}

As shown in Figure 4, hormone dependent transcriptional activation of the reporter gene chloramphenicol acethyltransferase (CAT) occurs in all transfected cell lines, independent of their ability to differentiate after VD treatment. The extent of VD-induced transcriptional activation was quantified by scintillation counting, expressed in arbitrary units and compared with CAT activities detectable in the same transfected cell lines but not VD treated. The mean of three different experiments was analysed and the variability of CAT positivity in the different experiments was lower than 0.5 arbitrary unit. The transcriptional activation varies slightly between the different cell lines, consisting of a fourfold increase in KG-1 and HL-60, a sixfold increase in NB4 and a sevenfold increase in THP-1 and K562.

\section{Transcriptional induction of genes associated with monocytic differentiation after a short treatment with VD}

To monitor the early stages of activation of the genetic program underlying monocytic differentiation, we have investigated, with the highly sensitive RT-PCR technique, the expression of genes associated with monocytic differentiation after $12 \mathrm{~h}$ treatment with VD. Among the primary VD responsive genes, i.e. genes carrying a functional VDRE, we have studied the expression of the hOC (Breen et al, 1994) and the p21 $21^{\text {waf- }}$ gene (Liu et al, 1996). Among the early responsive gene associated with the monocytic differentiation program we have studied the expression of CD14 (Zhang et al, 1994) and HMSE-1 (Uphoff et al, 1993). Results shown in Figure 5A, indicate that CD14 mRNA is induced by VD treatment only in AML-1, HL-60 (M2/M3 types of AML), THP-1 and U937 cells (M5 types of AML), that is in all the VD sensitive cell lines (Figure 5A, lanes $7-10$, and 13-16), but is not expressed in myelo-erythroid precursors (K562), M0/M1 early myeloblastic (KG-1a and KG-1) and in M3 promyelocytic cells (NB4), i.e. in the VD unresponsive cell lines (Figure 5A, lanes $1-6$ and 11,12$)$. HMSE-1 mRNA is not detected in VD

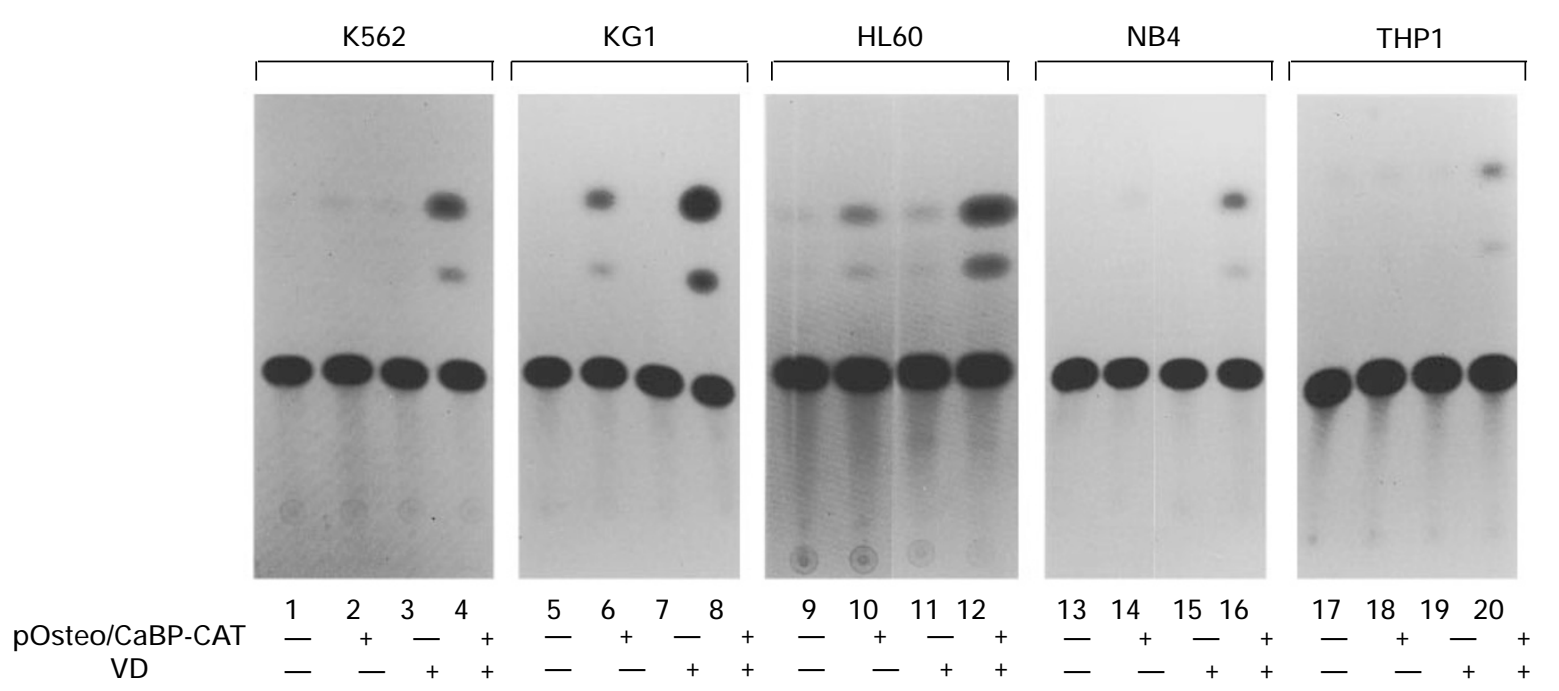

Figure 4 Cat assay from cell extracts of K562, KG1, HL60, NB4 and THP1 cell lines, evaluated after transfection with pOsteo/CaBP-CAT. Each assay was performed electroporating the cells without DNA (negative controls) in the absence (lanes 1, 5, 9, 13 and 17) or in the presence of VD (lanes $3,7,11,15$ and 19), or with plasmid DNA, in the absence (lanes 2, 6, 10,14 and 18) or in the presence of VD (lanes 4, 8, 12, 16 and 20). Normalization of the CAT assay was performed using different amounts of cell lysates based on the $\beta$-Gal activity of the co-transfected pMCV $\beta$ plasmid. The transcriptional activation varies slightly between the different cell lines, consisting of a fourfold increase in KG-1 and HL-60, a sixfold increase in NB4 and a sevenfold increase in THP-1 and K562. 
non-responsive cell lines (Figure 5B, lanes 1 to 6 ), whereas is constitutively expressed and not modulated by VD treatment in VD responsive cell lines (Figure 5B, lanes $7,8,11$ to 16 ) with the only exception of HL-60 cells where a clear induction is detected after VD treatment (Figure 5B, compare lanes 9 and 10). The p2 $1^{\text {waf-1 }} \mathrm{mRNA}$ is constitutively expressed in all cell lines (Figure 5C, lanes 1 to 8 and 11 to 14) with the exception of HL60 cells, where it is not detected (Figure 5C, lanes 9 and 10), and of U937, where a clear induction is observed after VD-treatment (Figure 5C, lanes 15 and 16). The hOC gene, which is a primary response gene in VDdependent osteblast differentiation (Hauschka et al, 1989), is clearly expressed in all the cell populations studied even if with different abundace (Figure 5D, lanes 1 to 16), but it is not related to monocytic differentiation. No modulation of $\beta-2$ microglobulin expression is detectable in the myeloid cell lines studied independently on VD treatment (Figure 5E, lanes $1-$ 16).

\section{Discussion}

AMLs are characterized by the clonal expansion of a precursor myeloid cell and by a differentiation block which occurs at different levels of maturation as characterized by the $\mathrm{FAB}$ and immunological classification (Bennett et al,

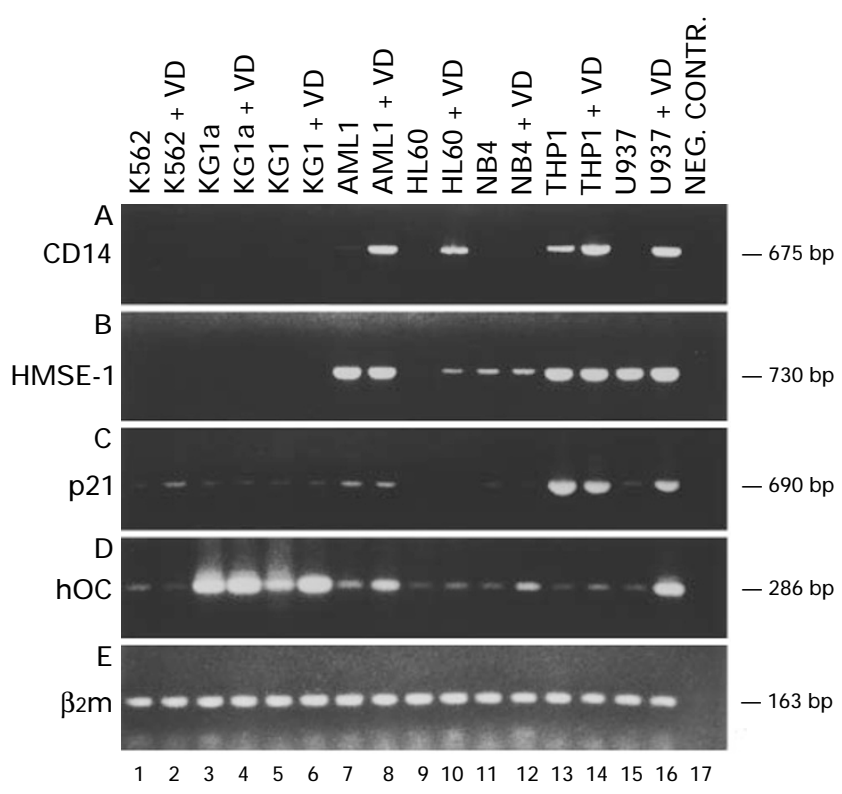

Figure 5 mRNA expression of CD14 antigen (A), HMSE (B), p21 waf-1 $(\mathbf{C})$, hOC (D) and $\beta 2-m$ (E) evaluated by RT - PCR technique in myeloid cell lines, before and after $12 \mathrm{~h}$ VD treatment. Ethidium bromide stained agarose gels are shown. Cell lines and VD treatment indicated at the top of the figure, are: proliferating (lane 1) and VD-treated (lane 2) K562 cells; proliferating (lane 3) and VD-treated (lane 4) KG1a cells; proliferating (lane 5) and VD-treated (lane 6) KG1 cells; proliferating (lane 7) and VD-treated (lane 8) AML1 cells; proliferating (lane 9) and VD-treated (lane 10) HL60 cells; proliferating (lane 11) and VD-treated (lane 12) NB4 cells; proliferating (lane 13) and VD-treated (lane 14) THP1 cells; proliferating (lane 15) and VD-treated (lane 16) U937 cells; lane 17: negative control obtained performing RT-PCR amplification without cDNA template. The sizes of the amplified gene fragments are indicated on the right side of the figure.
1976; Drexler, 1987). It is thus likely that the growth advantage of acute leukemia blast cells is realized not only through an increased proliferation rate, but also through the maturation arrest which leads to a prolonged survival and to a decreased rate of apoptosis (Torelli et al, 1994). Therefore, the induction of these neoplastic cells to differentiate and undergo apoptosis provides an opportunity to modify the course of the malignancy (Castaigne et al, 1990; Warrell, et al, 1991). Among the natural hematopoietic differentiation agents ATRA and VD are the most extensively studied in vitro and in vivo (Pols et al, 1990; De Luca, 1991). It is well known that the activity of these compounds is mediated by specific nuclear receptors which bind their cognate DNA responsive elements mostly as heterodimers with RXR and so activate gene transcription (Hsieh et al, 1995; Umesono et al, 1991; Ozono et al, 1990). The biological effect is the activation of genetic programs which lead to a decrease of proliferative activity mainly due to the induction of differentiation. However, AML blast cells, blocked at different levels of maturation, are not responsive to hematopoietic growth factors with differentiation activity alone, in vitro and in vivo, but can be sensitive to VD in particular when cytokines are also present (Trinchieri et al, 1987; Kelsey et al, 1992; Collins et al, 1977). It has been shown that receptor binding of VD occurs efficiently in immature myeloid cells (Feldman et al, 1993). To get insights into the correlations between genotypic and phenotypic effects of VD, we have compared the effect of VD in different myeloid cell lines either responsive or unresponsive to this hormone. The phenotypic effects of VD have been monitored by studying the morphology, adhesion capacity and expression of CD14 monocytic differentiation marker on the cell surface. The genotypic effects have been monitored by studying VDR expression and phosphorylation, VDR-dependent DNA binding and transactivation activities. Our results clearly indicate that early myeloblastic cell lines such as K562 (myelo-erythroblastic), KG-1a and KG-1 (M0-M1 type), and the more differentiated promyelocytic cell line NB4 (M3 type) are not responsive to the differentiation activity of VD, while the late myeloblastic AML- 1 and HL-60 cells (M2/M3 types), and monoblastic U937 (histiocytic) and THP-1 cells (M5 type), are induced to differentiate by VD. These observations indicate that a narrow window exists during the maturation of myeloid cells which is permissive to monocytic differentiation induced by VD. In fact, a clear phenotypic effect can be observed only in cellular contexts characterized by M2/M3 type and in monocyte precursor cells, such as the M5 type of leukemia.

VDR is clearly detected in the nuclear extracts of all cell lines after $12 \mathrm{~h}$ of treatment with VD even though the receptor abundance and the level of phosphorylation vary considerably. The hyperphosphorylated receptor $(53 \mathrm{kD})$ is mainly associated with a VD unresponsive phenotype. However, regardless of the phosphorylation levels, EMSA indicates that VDR, present in all nuclear extracts assayed, heterodimerizes with RXR and binds a VDRE-containing oligodeoxynucleotide. These data strongly indicate that, independently on VD phenotipic effects, VDR expression and DNA binding activity are maintained in all cell lines. 
This is confirmed by data showing that VD treatment increases transactivation of a VDRE-dependent reporter plasmid in K562, KG-1, HL-60, NB-4 and THP-1 cells.

Our data collectively indicate that in myeloid cells, arrested at different stages of differentiation, either responsive or non responsive to VD, VDR is expressed and is active in DNA binding and transcription promotion. However, since multiple factors such as chromatin structure, nucleosome organization and gene-nuclear matrix interactions, i.e. the cellular context, contribute to regulate gene transcription in vivo, we have studied the ability of VD to activate transcription of endogenous genes regulated by VDRE and of genes associated with terminal monocytic differentiation. Among the selected primary response genes, the hOC gene, which is mainly associated with osteoblast differentiation (Hauschka et al, 1989), and the p21 waf- 1 gene are not indicative of endogenous transactivation by VDR/RXR heterodimers since they are not strictly associated with monocyte differentiation. Instead, CD14 mRNA is clearly induced only in the cell lines with monocytic differentiation capacity and is not expressed in VD-unresponsive cell lines. The main feature of HMSE-1 mRNA expression is that it is not expressed in VD non responsive cells.

In summary, it appears that myeloid precursors at all stages of differentiation are equiped with the tools necessary for triggering the VD-dependent genetic program eventually leading to terminal differentiation. In other words, they contain a VDR which is fully active in binding its DNA site and in promoting transcription. This observation is particularly interesting since it is the first experimental evidence that early myeloblasts can transcribe nuclear receptors which undergo post-translational modification such as phosphorylation and nuclear translocation after VD treatment, and that in these cells, the nuclear abundance of VDR and RXR is sufficient to allow heterodimerization. Furthermore, in early myeloblast nuclei, VDR has functional DNA binding and transactivation domains. This VDR functional behavior was observed in all the myeloid cellular populations studied from early to late myeloblasts and monoblasts, independently of their VD dependent differentiation capacity, and seems to be a basic equipment of immature myeloid cells. Therefore, the lack of response to VD, which occurs at the early stages of differentiation, is likely to depend on steps located downstream of the VDR/DNA interaction. The analysis of VD-induction of primary response genes has not helped to clarify this point, since no clearcut correlation could be made between VD induction of these genes and the achievement of a terminally differentiated phenotype. This might not be surprising since myeloid-specific, VD primary response genes are not known at present. Therefore the discrepancies that we have observed between VDR function and VD induction of monocytic phenotype, might be the effect of the peculiarity of the different myeloid cellular contexts. Our data suggest that a narrow differentiation window permissive to monocytic differentiation exists in myeloid precursor cells at the M2/M3 maturation level which is not exclusively dependent on VDR function.

\section{Materials and Methods}

\section{Cell cultures and differentiation}

K562 (Lozzio and Lozzio, 1975), KG-1 (Koeffler and Golde, 1978), KG1a (Koeffler et al, 1980), HL-60 (Collins et al, 1977), THP-1 (Tsuchiya et al, 1980) and U937 (Sundstrom and Nilsson, 1976) cell lines were obtained from the American Tissue Culture Collection (Rockville, MD) and from the German Collection of Microorganisms and Cell Cultures (Braunschweig, Germany). NB4 promyelocytic cell line (Lanotte et al, 1991) has been obtained from Dr. Lanotte and AML-1 cell line was a kind gift of Dr Valtieri (Lange et al, 1987). Cells were grown in RPMI 1640 (Gibco, Paisley, UK), supplemented with 10\% heat-inactivated FCS (Boehringer, Mannheim, Germany), $2 \mathrm{mML}$-Glutamine, in $5 \% \mathrm{CO}_{2}$ atmosphere at $37^{\circ} \mathrm{C}$, and were passed twice a week. Cells were induced to differentiate by treatment with $10^{-7}$ M VD (Hoffman-Laroche, Basel, Switzerland) for $12 \mathrm{~h}$ or 5 days, depending on the different experiments performed. A blast cell population was obtained by leukapheresis from a patient with M5 type of leukemia before any pharmacological treatment. The blast cells were purified and characterized as already described (Ferrari et al, 1993). Monocytic differentiation was monitored primarily by studying the expression of CD14 (Zhang et al, 1994) and CD45 (Thomas, 1989) antigens by direct immunofluorescence with specific antibodies (anti CD45/CD14, Becton Dickinson, San Jose, CA, USA), and by RT - PCR (see RNA analysis in Materials and Methods) on CD14 and human monocytic specific esterase (HMSE-1) mRNAs (Uphoff et al, 1993). Flow cytometric analysis was performed as described (Manfredini et al, 1993). Morphology was assessed by cytocentrifugation followed by May Grunwald Giemsa (MGG) staining. The immunophenotype was assessed by using a standard panel of monoclonal $\mathrm{Ab}$ as described (Drexler, 1987).

\section{Nuclear extract preparation}

Nuclear extracts were obtained from the different myeloid cells as already described (Hennighausen and Lubon, 1987) before and after $12 \mathrm{~h}$ of VD treatment. Briefly the cells were centrifuged, washed in PBS and re-suspended in 5 vol. of $0.3 \mathrm{M}$ Sucrose, $10 \mathrm{mM}$ Hepes- $\mathrm{KOH} \mathrm{pH}$ 7.9, $10 \mathrm{mM} \mathrm{KCl}, 1.5 \mathrm{mM} \mathrm{MgCl} 2,0.1 \mathrm{mM}$ EGTA, $0.5 \mathrm{mM}$ dithiothreitol (DTT), $0.5 \mathrm{mM}$ phenylmethylsulfonylfluoride (PMSF), and $0.2 \mu \mathrm{g} / \mathrm{ml}$ each of antipain, leupeptin and pepstatin-A. Cells were then lysed in Dounce homogenizer by 10 strokes of $B$ pestle, followed by two strokes in the presence of $0.15 \%$ Nonidet P-40 (NP-40). Lysis was monitored by phase contrast microscopy. The nuclei were washed twice in the same buffer without NP-40, recovered by centrifugation at $1200 \times g$ for $10 \mathrm{~min}$ and then resuspended in $10 \mathrm{mM}$ Hepes-KOH pH 7.9, $400 \mathrm{mM}$ $\mathrm{NaCl}, 1.5 \mathrm{mM} \mathrm{MgCl}, 0.1 \mathrm{mM}$ EGTA, $0.5 \mathrm{mM}$ DTT, $5 \%$ glycerol, $0.5 \mathrm{mM}$ PMSF. After four strokes with B pestle, the homogenate was stirred for $30 \mathrm{~min}$ at $4^{\circ} \mathrm{C}$ followed by centrifugation for $60 \mathrm{~min}$ at $100000 \times \mathrm{g}$. The nuclear extracts were finally dialyzed for $4 \mathrm{~h}$ at $4^{\circ} \mathrm{C}$ against 100 vol. of $10 \mathrm{mM}$ Hepes- $\mathrm{KOH}$ pH 7.9, $75 \mathrm{mM} \mathrm{NaCl}, 0.1 \mathrm{mM}$ EDTA, $0.5 \mathrm{mM}$ DTT, $20 \%$ glycerol, $0.5 \mathrm{mM} \mathrm{PMSF}$, cleared by centrifugation at $25000 \times \mathrm{g}$ for $15 \mathrm{~min}$ at $4^{\circ} \mathrm{C}$, and stored at $-80^{\circ} \mathrm{C}$ in small aliquots. Protein concentration was evaluated by the Lowry method and the quality of the extract by PAGE. Dephosphorylation was obtained by diluting the nuclear extracts four-fold in gel shift buffer and incubating at $30^{\circ} \mathrm{C}$ for $30 \mathrm{~min}$ in the presence of 50 units of calf intestine alkaline phosphatase (CIAP) (Lefebvre et al, 1995).

\section{Western blotting}

Western blotting was performed using the Burnette method with minor modifications (Burnette, 1981). $50 \mu \mathrm{g}$ of nuclear extract were then 
dissolved in $1 \times$ reducing loading buffer $(50 \mathrm{mM}$ Tris $\mathrm{pH} 8,5 \% \beta$ mercaptoethanol, $2 \%$ SDS, $0.1 \%$ Bromophenol Blue, $10 \%$ glycerol), loaded onto $7.5-10 \%$ SDS-PAGE and electrophoresed in TGS buffer (25 mM Tris pH 8.3, $250 \mathrm{mM}$ glycine, $0.1 \%$ SDS). The separated proteins were transferred at $4^{\circ} \mathrm{C}$ onto a nitrocellulose sheet by electroblotting in TGM buffer $(25 \mathrm{mM}$ Tris $\mathrm{pH} 8.3,250 \mathrm{mM}$ glycine, $20 \%$ methanol) for $2 \mathrm{~h}$ at $1 \mathrm{~A}$. In order to monitor the electroblotting efficiency the membrane was stained in $0.2 \%$ Ponceau $\mathrm{S} / 0.3 \%$ TCA and destained in $0.3 \%$ TCA. Membranes were pretreated with TBST blocking solution (10 mM Tris $\mathrm{pH} 8,150 \mathrm{mM} \mathrm{NaCl}, 0.05 \%$ Tween 20 , supplemented with $4 \mathrm{mg} / \mathrm{ml}$ normal serum) for $1 \mathrm{~h}$ at r.t., incubated with the primary antibody $(1: 500)(1 \mathrm{~h}$ at r.t.) and then with the indicated HRP-conjugated secondary antibody $(1: 5000)(1 \mathrm{~h}$ at r.t.) in blocking solution. The $9 A 7 \gamma$ rat monoclonal anti-VDR (ABR, affinity bioreagents, Golden $\mathrm{CO}$ ) was used as primary antibody for the detection of VDR protein. The detection was carried out by the ECL chemiluminescence method (Amersham Life Science, Little Chalfont, England).

\section{Gel shift assay}

Oligonucleotides were synthesized with an automated solid phase DNA synthesizer (Applied Biosystem, Inc., Foster City, CA; Mod. 394) with the standard phosphoramidite chemistry and purified by PAGE followed by electroelution as described (Manfredini et al, 1993). The following single stranded oligomers and their complement were synthesized to be used as probes in the gel shift assay: $5^{\prime}$ TGCCCTGCACTGGGTGAATGAGGACATTACTGACC-3', rat osteocalcin VDRE (Umesono et al, 1991); 5'-TCTAGGTGACTCACCGGGTGAACGGGGGCATTGCGAG, human osteocalcin VDRE (Ozono et al, 1990); 5'-AGCTTCAGGTCAAGGAGGTCAGAGAGC, DR3 (Umesono et al, 1991). Oligonucleotide annealing was performed as already described (Kadonaga and Tjian, 1986). The double stranded oligodeoxynucleotides were further purified by PAGE and electroelution, and, $5^{\prime}$ end labeled $(100 \mathrm{ng})$ as already described (Ferrari et al, 1994). The mixture was incubated at $37^{\circ} \mathrm{C}$ for $1 \mathrm{~h}$ followed by addition of $80 \mu \mathrm{l} 50 \mathrm{mM}$ EDTA, extraction with $1 \mathrm{vol}$ of $1: 1$ phenol/chloroform and ethanol precipitation. Specific radioactivities ranged from 1 to $3 \times 10^{8}$ c.p.m. $/ \mu \mathrm{g}$ DNA. The gel shift retardation assay was performed as already described (Ferrari et al, 1994). Briefly: nuclear extracts (15 $\mu \mathrm{g}$ protein) were incubated with $5 \mu \mathrm{g}$ poly (I.C) (Pharmacia, Piscataway, $\mathrm{NJ}$ ), for $20 \mathrm{~min}$ at room temperature in $1 \times$ a gel shift buffer (10 mM Tris- $\mathrm{HCl} \mathrm{pH} \mathrm{7.5,50} \mathrm{mM} \mathrm{KCl,} 5 \mathrm{mM} \mathrm{MgCl}$, 1 mM DTT, $1 \mathrm{mM}$ EDTA and $15 \%$ glycerol). The labeled oligonucleotide was then added $(1 \mathrm{ng})$ and the incubation continued for a further $30 \mathrm{~min}$ (final volume $20 \mu \mathrm{l})$. When indicated, specific antibodies were added to the incubation mixture $10 \mathrm{~min}$ before the addition of the probe. The following antibodies were used: 9A7 $\gamma$ (rat monoclonal anti-VDR, ABR, affinity bioreagents, Golden CO); 4RX-1D12 (mouse monoclonal anti$\operatorname{RXR} \alpha,-\beta,-\gamma$, kindly provided by Dr. P. Chambon). In all the gel mobility shift experiments the VDR specificity of the shifted bands was confirmed by the disruption of the band when anti-VDR monoclonal antibody was added. In several control experiments VDRE specificity was also confirmed by adding 100 -fold excess cold VDRE oligonucleotides. The use of anti-RXR $\alpha$ monoclonal antibody has the ability to demonstrate a supershifted band when the $R X R \alpha$ is complexed with VDR in an heterodimeric conformation. All the antibodies were added to the samples at 1:20 dilution. The reaction mixtures were then electrophoresed on a $5 \%$ polyacrylamide gel in $0.5 \times$ TBE ( $45 \mathrm{mM}$ Tris base, $45 \mathrm{mM}$ boric acid, $1 \mathrm{mM}$ EDTA), prerun for $1 \mathrm{~h}$ at room temperature. Finally the gel was fixed, vacuum dried, and exposed to X-ray films $(2-4 \mathrm{~h})$.

\section{RNA analysis}

Total cellular RNA was extracted using a modification of the guanidinium-cesium chloride centrifugation technique (MacDonald et al, 1987), and digested with RQ1-DNAse (Promega, Madison, WI) to avoid DNA contamination as already described (Grande et al, 1995). RT-PCR reactions were carried out using a modification of a previously described technique (Ferrari et al, 1993). Briefly $3 \mu \mathrm{g}$ of total RNA extracted from each sample was reverse transcribed using $400 \mathrm{U}$ of M-MLV Reverse Transcriptase (GIBCO, BRL, Gaithersburg, $\mathrm{MD}$ ) and $1 \mu \mathrm{g}$ of OligodT15 primer (Boehringer Mannheim GmbH Biochemica, Mannheim, Germany) for $1 \mathrm{~h}$ at $42^{\circ} \mathrm{C}$ in $1 \times \mathrm{RT}$ buffer (50 mM Tris pH 8.3, $60 \mathrm{mM} \mathrm{KCl}, 1.5 \mathrm{mM} \mathrm{MgCl} 2,10 \mathrm{mM}$ DTT, $1 \mathrm{mM}$ dATP, dCTP, dGTP, dTTP, 20 U RNAsin, $0.1 \mathrm{mg} / \mathrm{ml} \mathrm{BSA}$ ), in a total volume of $30 \mu \mathrm{l}$. The CDNA was then heated at $95^{\circ} \mathrm{C}$ for $3 \mathrm{~min}$ and stored at $4^{\circ} \mathrm{C}$. $1 \mu \mathrm{l}$ of $\mathrm{CDNA}$ was amplified adding $2.5 \mathrm{U}$ of Taq polymerase (Boehringer, Mannheim, Germany), $0.5 \mu \mathrm{g}$ of specific direct primer (DP) and reverse primer (RP) in a total volume of $50 \mu \mathrm{l}$, in $10 \mathrm{mM}$ Tris pH 8.3, $50 \mathrm{mM} \mathrm{KCl}, 1.5 \mathrm{mM} \mathrm{MgCl}_{2}, 200 \mu \mathrm{M}$ dNTPs. The amplification was carried out using 20-40 cycles under the following conditions: denaturation at $95^{\circ} \mathrm{C}$ for $45 \mathrm{~s}$; annealing at $55^{\circ} \mathrm{C}$ for $2 \mathrm{~min}$; extension at $72^{\circ} \mathrm{C}$ for $3 \mathrm{~min}$. $10 \mu \mathrm{l}$ of each sample was then electrophoresed on a $2 \%$ agarose gel. RT-PCR analysis was performed using oligodeoxy-nucleotide primers specific for CD14 antigen (Ferrero and Goyert, 1988), HMSE-1 (Zschunke et al, 1991), p21 $1^{\text {waf- }}$ (el Deiry et al, 1993), human osteocalcin (hOC) (Kiefer et al, $1990)$ and $\beta 2$ microglobulin $(\beta 2 \mathrm{~m})$ (Suggs et al, 1992). The oligonucleotides used as direct primer (DP) or reverse primer (RP) were: CD14-DP, 5'-TCCAGAGCCTG-TCCGGAGCTCAGA-3'; CD14RP, 5'-GCGTTCGCCCAGTCCAGGATTGTCA-3'; HMSE1-DP, 5'CCTCCTATGTGCACCCAAGAT-3'; HMSE1-RP, 5'-GCATCCCATCAATCACAGTGC-3'; p21 waf-1-DP, 5'-AGTTCCTTGTGGAGCCGGAGCTGGG-3'; p2 $1^{\text {waf-1 }}$-RP, 5'-TCCAGGACTGCAGGCTTCCTGTGGG-3'; hOC-DP, 5'-GAGCCCTCACAC-TCCTCGCCCTATT3'; hOC-RP, 5'-GTAGAAGCGCCGATAGGCCTCCTGA-3'; $\beta 2 \mathrm{~m}$-DP, 5'-CTCGCGCTACTCTCTCTTTCT-3'; $\beta 2 m-R P, 5^{\prime}$-TCCATTCTTCAGTAAGTCAACT-3'.

\section{Cell transfection}

We used the following plasmids in the transfection experiments: $\mathrm{pMCV} \beta$ (Clontech Laboratories Inc, Palo Alto, CA, USA), a plasmid capable of expressing $E$. coli $\beta$-galactosidase under the control of cytomegalovirus immediate early promoter/enhancer; pOsteo/CABP-CAT containing the chloramphenicol acetyltransferase (CAT) reporter gene under the control of the VDRE of the human ostecalcin gene $(-511 /$ -480 ) and the minimal promoter region of the chicken Calbindin gene (Ferrari et al, 1990). VD treatment of Rat Osteosarcoma (ROS) cells transfected with this plasmid causes a 6-8 fold induction of CAT reporter activity as compared to untreated cells. The obtained $\beta$-GAL activity values were used in all transfection experiments to normalize for transfection efficiency. K562, KG-1, HL60, NB-4 and THP-1 cells were maintained in RPMI 1640 medium with $5 \%$ fetal calf serum (FCS). $2.5 \times 10^{7}$ cells were transfected by electroporation with $30 \mu \mathrm{g}$ of pOsteo/CABP-CAT plasmid and $3 \mu \mathrm{g}$ of pMCV $\beta$ plasmid. Electroporation was performed at $250 \mathrm{~V}, 960 \mu \mathrm{F}$ (Gene Pulser Apparatus, Bio Rad). Transfected cells were cultured in RPMI medium containing 15\% FCS with or without VD for $48 \mathrm{~h}$ and then harvested for CAT assay. In relationship to the transfection efficacy, as determined by the $\beta$-Galactosidase activity of the cotransfected plasmid, normalization was performed using different amounts of cellular extracts in the CAT assay. This assay was performed and quantified by scintillation counting as already described (Alam and Cook, 1990). 


\section{Acknowledgements}

This work was supported by a grant from A.I.R.C. (Associazione Italiana per la Ricerca sul Cancro) and by a grant from CNR (Consiglio Nazionale delle Ricerche; PF: ACRO).

\section{References}

Alam J and Cook JL (1990) Reporter genes: application to the study of mammalian gene transcription. Anal. Biochem. 188: 245-254

Bennett JM, Catovsky D, Daniel MT, Flandrin G, Galton DA, Gralnick HR, Sultan C (1976) Proposals for the classification of the acute leukaemias. FrenchAmerican-British (FAB) co-operative group. Br J Haematol 33: 451-458

Breen EC, van Wijnen AJ, Lian JB, Stein GS, Stein JL (1994) In vivo occupancy of the vitamin $D$ responsive element in the osteocalcin gene supports vitamin Ddependent transcriptional upregulation in intact cells. Proc. Natl. Acad. Sci. USA 91: $12902-12906$

Brown TA and DeLuca HF (1990) Phosphorylation of the 1,25-dihydroxyvitamin D3 receptor. A primary event in 1,25-dihydroxyvitamin D3 action. J. Biol. Chem. 265: $10025-10029$

Burnette WN (1981) 'Western blotting': electrophoretic transfer of proteins from sodium dodecyl sulfate-polyacrylamide gels to unmodified nitrocellulose and radiographic detection with antibody and radioiodinated protein A. Anal. Biochem. 112: 195-203

Castaigne S, Chomienne C, Daniel MT, Ballerini P, Berger R, Fenaux P, Degos L (1990) All-trans retinoic acid as a differentiation therapy for acute promyelocytic leukemia: clinical results. Blood 76: 1704-1709

Collins SJ, Gallo RC, Gallagher RE (1977) Continuous growth and differentiation of human myeloid leukaemic cells in suspension culture. Nature 270: 347-349

De Luca LM (1991) Retinoids and their receptors in differentiation, embryogenesis, and neoplasia. Faseb. J. 5: 2924-2933

Delva L, Cornic M, Balitrand N, Guidez F, Miclea JM, Delmer A, Teillet F, Fenaux P, Castaigne S, Degos L, et al (1993) Resistance to all-trans retinoic acid (ATRA) therapy in relapsing acute promyelocytic leukemia: study of in vitro ATRA sensitivity and cellular retinoic acid binding protein levels in leukemic cells [see comments]. Blood 82: 2175-2181

Dermime S, Grignani F, Clerici M, Nervi C, Sozzi G, Talamo GP, Marchesi E, Formelli F, Parmiani G, Pelicci PG, et al (1993) Occurrence of resistance to retinoic acid in the acute promyelocytic leukemia cell line NB4 is associated with altered expression of the pml/RAR alpha protein. Blood 82: 1573-1577

Dore BT, Momparler RL (1996) Mutation in the ligand-binding domain of the retinoic acid receptor alpha in $\mathrm{HL}-60$ leukemic cells resistant to retinoic acid and with increased sensitivity to vitamin D-3 analogs. Leuk. Res. 20: 761 - 769

Drexler HG (1987) Classification of acute myeloid leukemias-a comparison of FAB and immunophenotyping. Leukemia 1: 697-705

Duits AJ, Dimjati W, van de WinkelJG, CapelPJ(1992) Synergism of interleukin 6 and 1 alpha,25-dihydroxyvitamin D3 in induction of myeloid differentiation of human leukemic cell lines. J. Leukoc. Biol. 51: 237-243

el Deiry WS, Tokino T, Velculescu VE, Levy DB, Parsons R, Trent JM, Lin D, Mercer WE, Kinzler KW, Vogelstein B (1993) WAF1, a potential mediator of p53 tumor suppression. Cell 75: $817-825$

Feldman J, Federico MH, Sonohara S, Katayama ML, Koike MA, Roela RA, da Silva MR, Brentani MM (1993) Vitamin D3 binding activity during leukemic cell differentiation. Leuk. Res. 17: 97-101

Ferrari S, Battini R, Molinari S (1994) Specific binding to vitamin D response elements of chicken intestinal DNA-binding activity is not related to the vitamin $D$ receptor. Mol. Endocrinol. 8: 173-181

Ferrari S, Battini R, Pike WJ (1990) Functional analysis of the promoter region of the gene encoding chicken calbindin D28K. Adv. Exp. Med. Biol. 269: 21-25

Ferrari S, Donelli A, Manfredini R, Sarti M, Roncaglia R, Tagliafico E, Rossi E, Torelli G, Torelli U (1990) Differential effects of c-myb and c-fes antisense oligodeoxynucleotides on granulocytic differentiation of human myeloid leukemia HL60 cells. Cell Growth Differ. 1: 543-548

Ferrari S, Grande A, Manfredini R, Tagliafico E, Zucchini P, Torelli G, Torelli U (1993) Expression of interleukins 1, 3, 6, stem cell factor and their receptors in acute leukemia blast cells and in normal peripheral lymphocytes and monocytes. Eur. J. Haematol. 50: 141-148
Ferrari S, Narni F, Mars W, Kaczmarek L, Venturelli D, Anderson B, Calabretta B (1986) Expression of growth-regulated genes in human acute leukemias. Cancer Res. 46: 5162-5166

Ferrari S, Tagliafico E, Ceccherelli G, Selleri L, Calabretta B, Donelli A, Temperani P, Sarti M, Sacchi S, Emilia G, et al (1989) Expression of the myeloperoxidase gene in acute and chronic myeloid leukemias: relationship to the expression of cell cycle-related genes. Leukemia 3: 423-430

Ferrero E and Goyert SM (1988) Nucleotide sequence of the gene encoding the monocyte differentiation antigen, CD14. Nucleic. Acids. Res. 16: 4173

Francis GE and Cunningham JM (1991) Growth and differentiation control. In: Pinedo $\mathrm{HM}$, Longo DL, Chabner BA eds Cancer chemotherapy and biological response modifiers annual 12. Elsevier Science Publishers, pp. 251-290

Grande A, Manfredini R, Tagliafico E, Balestri R, Pizzanelu M, Papa S, Zucchini P, Bonsi L, Bagnara G, Torelli U, Ferrari S (1995) All trans retinoic acid induces simultaneously granulocytic differentiation and expression of inflammatory cytokines in HL60 cells Exp. Hematol. 23(2): 117-125

Hauschka PV, Lian JB, Cole DE, Gundberg CM (1989) Osteocalcin and matrix Gla protein: vitamin K-dependent proteins in bone. Physiol. Rev. 69: 990-1047

Hennighausen L and Lubon H (1987) Interaction of protein with DNA in vitro. Methods Enzymol. 152: $721-735$

Hsieh JC, Nakajima S, Galligan MA, Jurutka PW, Haussler CA, Whitfield GK, Haussler MR (1995) Receptor mediated genomic action of the 1,25(OH)(2)D-3 hormone expression of the human vitamin D receptor in E-Coli. Journal of Steroid Biochemistry \& Molecular Biology 53: 583-594

Imai Y, Pike JW, Koeffler HP (1995) Potent vitamin D3 analogs: their abilities to enhance transactivation and to bind to the vitamin D3 response element. Leuk. Res. 19: 147-158.

Jin CH, Kerner SA, Hong MH, Pike JW (1996) Transcriptional activation and dimerization functions in the human vitamin D receptor. Molecular Endocrinology 10: $945-957$

Kadonaga JT and Tjian R (1986) Affinity purification of sequence-specific DNA binding proteins. Proc. Natl. Acad. Sci. USA 83: 5889-5893

Kasukabe T, Honma Y, Hozumi M, Suda T, Nishii Y (1987) Control of proliferating potential of myeloid leukemia cells during long-term treatment with vitamin D3 analogues and other differentiation inducers in combination with antileukemic drugs: in vitro and in vivo studies. Cancer Res. 47: 567-572

Kelsey SM, Makin HL, Newland AC (1992) Functional significance of induction of differentiation in human myeloid leukaemic blasts by 1,25-dihydroxyvitamin D3 and GM-CSF. Leuk. Res. 16: 427-434

Kiefer MC, Saphire AC, Bauer DM, Barr PJ (1990) The cDNA and derived amino acid sequences of human and bovine bone Gla protein. Nucleic. Acids. Res. 18: 1909

Koeffler HP, Billing R, Lusis AJ, Sparkes R, Golde DW (1980) An undifferentiated variant derived from the human acute myelogenous leukemia cell line (KG-1). Blood 56: 265-273

Koeffler HP and Golde DW (1978) Acute myelogenous leukemia: a human cell line responsive to colony-stimulating activity. Science 200: 1153-1154

Lange B, Valtieri M, Santoli D, Caracciolo D, Mavilio F, Gemperlein I, Griffin C, Emanuel B, Finan J, Nowell P, et al (1987) Growth factor requirements of childhood acute leukemia: establishment of GM-CSF-dependent cell lines. Blood 70: 192-199

Lanotte M, Martin Thouvenin V, Najman S, Balerini P, Valensi F, Berger R (1991) NB4, a maturation inducible cell line with $\mathrm{t}(15 ; 17)$ marker isolated from a human acute promyelocytic leukemia (M3). Blood 77: 1080-1086

Lea MA (1992) Action of exogenous differentiating agents on gene expression in cancer cells. Crit. Rev. Oncol. Hematol. 13: 189-214

Lefebvre P, Gaub MP, Tahayato A, Rochette Egly C, Formstecher P (1995) Protein phosphatases 1 and $2 A$ regulate the transcriptional and DNA binding activities of retinoic acid receptors. J. Biol. Chem. 270: 10806-10816

Lemon BD, Freedman LP (1996) Selective effects of ligands on vitamin D-3 receptorand retinoid $x$ receptor-mediated gene activation in vivo. Molecular \& Cellular Biology 16: $1006-1016$

Liu M, Lee MH, Cohen M, Bommakanti M, Freedman LP (1996) Transcriptional activation of the Cdk inhibitor p21 by vitamin D3 leads to the induced differentiation of the myelomonocytic cell line U937. Genes Dev. 10: 142153

Lozzio CB and Lozzio BB (1975) Human chronic myelogenous leukemia cell-line with positive Philadelphia chromosome. Blood 45: 321-334

Lubbert M, Herrmann F, Koeffler HP (1991) Expression and regulation of myeloidspecific genes in normal and leukemic myeloid cells. Blood 77: 909-924 
MacDonald RJ, Swift GH, Przybyla AE, Chirgwin JM (1987) Isolation of RNA using guanidinium salts. Methods Enzymol. 152: 219-227

Manfredini R, Grande A, Tagliafico E, Barbieri D, Zucchini P, Citro G, Zupi G, Franceschi C, Torelli U, Ferrari S (1993) Inhibition of c-fes expression by an antisense oligomer causes apoptosis of HL60 cells induced to granulocytic differentiation. J. Exp. Med. 178: 381-389

Miller CW and Koeffler HP (1990) In vivo and in vitro differentiation of myeloid leukemic cells. In: Mauer AM (ed) The biology of human leukemia. (Baltimore and London, The John Hopkins University Press) pp. 152-176

Okabe-Kado J, Honma Y, Hayashi M, Hozumi M (1991) Effects of transforming growth factor-beta and activin A on vitamin D3-induced monocytic differentiation of myeloid leukemia cells. Anticancer Res. 11: 181186

Ozono K, Liao J, Kerner SA, Scott RA, Pike JW (1990) The vitamin D-responsive element in the human osteocalcin gene. Association with a nuclear protooncogene enhancer. J. Biol. Chem. 265: 21881-21888

Pols HA, Birkenhager JC, Foekens JA, van Leeuwen JP (1990) Vitamin D: a modulator of cell proliferation and differentiation. J. Steroid Biochem. Mol. Biol. 37: $873-876$

Suggs SV, Wallace RB, Hirose T, Kawashima EH, Itakura K (1992) Use of synthetic oligonucleotides as hybridization probes: isolation of cloned cDNA sequences for human beta 2-microglobulin. 1981 [classical article]. Biotechnology 24: 140 144

Sundstrom C and Nilsson K (1976) Establishment and characterization of a human histiocytic lymphoma cell line (U-937). Int. J. Cancer 17: 565-577

Thomas ML (1989) The leukocyte common antigen family. Annu. Rev. Immunol. 7 $339-369$

TorelliU, FerrariS, Manfredini R(1994) Proliferation, differentiation and programmed cell death: an outline of their genetic control and disorders in normal and leukemic myelopoiesis. In: Cacciola E, Deisserroth AB, Giustolisi R eds Hemopoietic growth factors, oncogenes and cytokines in clinical hematology. (Basel, Basel Karger) pp. $49-63$
Trinchieri G, Rosen M, Perussia B (1987) Induction of differentiation of human myeloid cell lines by tumor necrosis factor in cooperation with 1 alpha,25dihydroxyvitamin D3. Cancer Res. 47: 2236-2242

Tsuchiya S, Yamabe M, Yamaguchi Y, Kobayashi Y, Konno T, Tada K (1980) Establishment and characterization of a human acute monocytic leukemia cell line (THP-1). Int. J. Cancer 26: 171-176

Umesono K, Murakami KK, Thompson CC, Evans RM (1991) Direct repeats as selective response elements for the thyroid hormone, retinoic acid, and vitamin D3 receptors. Cell 65: $1255-1266$

Uphoff CC, Gignac SM, Metge K, Zschunke F, Radzun HJ, Drexler HG (1993) Expression of the monocyte-specific esterase gene in leukemia-lymphoma cell lines. Leukemia 7: 58-62

Warrell RP, Jr., Frankel SR, Miller WH, Jr., Scheinberg DA, Itri LM, Hittelman WN, Vyas R, Andreeff M, Tafuri A, Jakubowski A, etal (1991) Differentiation therapy of acute promyelocytic leukemia with tretinoin (all-trans-retinoic acid). N. Engl. J. Med. 324: $1385-1393$

Zhang DE, Hetherington CJ, Gonzalez DA, Chen HM, Tenen DG (1994) Regulation of CD14 expression during monocytic differentiation induced with 1 alpha,25dihydroxyvitamin D3. J. Immunol. 153: 3276-3284

Zschunke F, Salmassi A, Kreipe H, BuckF, Parwaresch MR, Radzun HJ(1991)cDNA cloning and characterization of human monocyte/macrophage serine esterase1. Blood 78: $506-512$ 